a new formulation of etomidate with thiopental side effects and awakening times. Anesthesiology 50: 242 (1979)

11. SimpSon, M.E. Pharmacokinetics of Althesin - a comparison with lignocaine. $\mathrm{Br}$. J. Anaes. 50: 1231 (1978)

12. Dunn, G.L., Morison, D.H., MCChesney, J., Pine, W., Kumana, C.R. \& Gupta, R.N. The pharmachokinetics and pharmacodynamics of minaxolone. Anesthesiology 53: S48 (1980).

13. Sear, J.W. \& MCGivan, J.D. Cytotoxicity of i v. anaesthetic agents on the isolated rat hepatocyte. Br. J. Anaes. 51: 733 (1979).

\section{Oxygen Analysers as Disconnection ALARM}

DEAR Sir,

Re: Use of Oxygen Analysers as a Disconnection

Alarm.

The Canadian Standards Association publication "Pulse" No. 20, May 1981 comments on the new standard for Oxygen Analysers as follows: "this device can be an effective disconnection alarm as well as an aid to regulating the oxygen level." We have considerable anxiety concerning the suggestion that an oxygen analyser should be used as a disconnection alarm.

An oxygen analyser inserted in the anaesthesia breathing circuit measures the oxygen concentra- tion at the point in the circuit which is being monitored. A satisfactory concentration at that point does not imply flow and the analyser will alarm only if the oxygen concentration at that point falls below a preset figure. Whether or not the oxygen concentration falls at the point being monitored, when a disconnection occurs, will depend in part on the following factors:

(a) the type of anaesthetic breathing circuit in use,

(b) the position of the analyser sensor in relation to the point of disconnection and the point of fresh gas inflow in that circuit.

(c) whether the patient is breathing spontaneously or whether ventilation is being controlled and the type of ventilator in use.

To be able to monitor whether the patient is in fact receiving the oxygen which is being delivered would require a separate system, which would have to be independent of the delivery system.

We consider that the use of an oxygen analyser in the delivery system to infer the integrity of the system is fraught with danger.

Malcolm M. Marks, M.D., F.R.C.P.(C), F.R.H. Wrigley, M.B., B.S., F.R.C.P.(C), Department of Anaesthesia,

The Wellesley Hospital, Toronto, Ontario.

\title{
CORRECTION
}

Morison, D.H., - A double-blind comparison of carbonated lidocaine and lidocaine hydrochloride in epidural anaesthesia. Can. Anaesth. Soc. Jour. 28: 387 (July 1981)

Page 387, 5th line from the end of the "Methods" section should read with an $\alpha$ error of 0.05 and a $\beta$ error of 0.1 